\title{
Study of the flavonoids of Anemone obtusiloba in the alpine meadow and the adaptation mechanism to the environment based on metabolic pathways
}

Lv Wanling ( $\sim$ 413958876@qq.com )

Tianshui Normal University

Liu Zuojun

Lanzhou University of Technology

\section{Research Article}

Keywords: Anemone obtusiloba, flavonoids, HPLC, LC-MS

Posted Date: February 3rd, 2022

DOI: https://doi.org/10.21203/rs.3.rs-1233697/v1

License: (c) (1) This work is licensed under a Creative Commons Attribution 4.0 International License.

Read Full License 


\section{Abstract}

In this study, the main pigment composition of Anemone obtusiloba was analysed by UV-vis spectrophotometry, HPLC, and LC-MS. The results showed that there were two kinds of pigmentsin $A$. obtusiloba, carotenoids, and flavonoids The absorbance spectra regularly changed with the depth of flower colour. Based on HPLC and LC-MS analyses, seven kinds of flavonoids were inferred, including luteolin-3-7-0-glucoside, quercetin-3-0-rutoside, quercetin-3-0-galactoside, quercetin-3-0-glucoside, quercetin-3-0-rhamnoside, kaempferol-3-0-sophoroside, and myricetin-3-0-rhamnose, and the derivative of quercetin was identified as the main component in A. obtusiloba. Besides, according to the analysis of the flavonoid metabolism pathway, it could be determined that flavonoid 3'-hydroxylase ( $\left(\mathrm{F}^{\prime} \mathrm{H}\right)$ was the key enzyme to increase the content of quercetin. This paper speculates that $A$. obtusiloba increases the content of quercetin by regulating flavonoid F3' $\mathrm{H}$, so that it can deepen the flower colour to adapt to the environment.

\section{Introduction}

Anemone obtusiloba, commonly known as Padar, Rattanjog, or Kawashud, is a flowering plant of the family Ranunculaceae and a densely tuftedperennial herb [1].It is native to the Himalayan and mountainous regions of Myanmaroccurring in the Alpine Himalaya from Kashmir to Sikkim at 2100-4200 $\mathrm{m}$ altitude and in the Nilgirihills at an altitude above $1800 \mathrm{~m}$ [2]. It bears buttercup hermaphrodite flower and the stem is short and tufted with a single terminal flower, generally producing one to three individual stems with yellow, light-yellow, or white colour. At present, research mainly focuses on the medicinal value of $A$. obtusiloba, whose ethanolic extract contains saponins (obtusilobinin, obtusilobin [3], and obtusilobicinin [4]). It also contains protoanemonin, which is an irritating acrid oil and is an enzymatic breakdown product of the glycoside ranunculin [5]. A. obtusiloba is used as a purgative and in the treatment of rheumatic joints, jaundice, spleen disorders, and anxiety neurosis. Besides, it is also used as an antidote to snakebite, while its seed oil is used to cure arthritis $[6,7]$. However, there are few studies on its petal pigment.

In the Tibetan Plateau, A. obtusiloba has its own adaptive mechanism to the local environment. During the past years, there have been significant environmental changes in the plateau area, with an obvious decrease of white flowers and an increase of yellow and light-yellow flowers of $A$. obtusiloba. It is speculated that this phenomenon may be related to its adaptability to the environment and biological evolution. Flower colour is one of the most important traits of plants and is attributed to various pigments that are composed of three major classes of compounds including flavonoids, carotenoids, and anthocyanin [8]. Among these compounds, flavonoids are responsible for the yellow colour. At the same time, the number and position of phenolic groups in the chemical structure have a certain influence on the flower colour. The colour of the flower will change from yellow to orange and to red by the hydroxylation at $\mathrm{C}_{3}$ [9]. However, increasing the hydroxylation of the $\mathrm{B}$ ring will change the colour to blue, and the methylation of the $B$ ring will make it red [10]. Carotenoids are responsible for colours ranging from 
yellow to red [11]. Cyanidin, which controls red, blue, purple, and other colours, can be divided into three types: pelargonidin, delphinidin, and anthocyanins [12].

Flavonoids represent a large subgroup of plant secondary metabolites including flavones, isoflavones, anthocyanins, flavanols, flavonols, and derivatives $[13,14]$ with various biological activities such as antiinflammation, anti-cancer, etc. [15]. Over the past decade, studies have revealed the core biosynthesis pathways of flavonoids in various plants such as Arabidopsis [16], Lactuca sativa [17], Camellia sinensis [18], Salvia miltiorrhiza [19], Oroxylum indicum [20], Chrysanthemum morifolium [21], Chrysanthemum indicum, and Scutellaria baicalensis [22, 23]. Flavones are synthesized via the flavonoid pathway, which is part of phenylpropanoid metabolism [24]. Naringenin is a central intermediate in the biosynthesis of normal 4'-hydroxyflavones [25]. The enzymatic properties related to flavonoid accumulation in vitro have been confirmed [26]. Flavonoid biosynthetic genes can be classified into two categories: (i) early biosynthetic genes, such as genes encoding phenylalanine ammonia lyase (PAL), chalcone synthase (CHS), and chalcone isomerase ( $\mathrm{CHI}$ ); (ii) late biosynthetic genes, such as those encoding flavanone 3hydroxylase (F3'H), dihydroflavonol reductase (DFR), and anthocyanidin synthase (ANS) [27]. CHS, the first key enzyme in the anthocyanin synthesis pathway, is affected by multiple factors, such as environmental stress, light, inducer, etc. [28]. There are six genes involved in anthocyanin synthesis in different tissues of grape, CHS, CHI, F3'H, DFR, leucoanthocyanidin reductase (LAR), and flavonoids glycosyltransferase (UFGT), while the accumulation of anthocyanidin is absent in white grape. Therefore, the accumulation of anthocyanidin is not only related to tissue, but also related to the alternative gene expression. The study aimed to qualitatively and quantitatively identify the chemical composition using different analytical methods including ultraviolet-visible (UV-vis) spectroscopy, HPLC, and LC-MS, and to further analyse the key enzyme synthesizing this pigment.

\section{Materials And Methods}

\subsection{Materials}

The experimental materials light-yellow and yellow A. obtusiloba were collected in early July at the peak of flowering from Maqu County, Gansu Province of China (101.52E, 33.40N). The flowers were rinsed, and the stamens were removed. After fixating at $80^{\circ} \mathrm{C}$ for $30 \mathrm{~min}$, they were dried at $60^{\circ} \mathrm{C}$ and crushed into powder with a pulveriser (Tianjin Taisite Instrument Co. Ltd., Tianjin, China). Then the powder sample was stored in a sealed bag and kept in a dark place before using.

\subsection{Spectral analysisbyUV-visspectroscopy 2.2.1 Spectral analysis of flavonoids}

The flavonoid extraction was identified according to the method of Murugesan et al. [29] with some modifications. To extract flavonoids, $0.1 \mathrm{~g}$ of flower powder was treated with methanol/formic acid (98:2, $\mathrm{v} / \mathrm{v}$ ) for $24 \mathrm{~h}$ in a Soxhlet apparatus under dark conditions. The filter residue was repeatedly extracted by the solvent. After the filtrate was combined and diluted to $10 \mathrm{~mL}$, the spectral scanning was carried out by 
a UV spectrophotometer (UV-3000, Shanghai JiaPeng technology Co., Ltd., Shanghai, China) with a range of $200-700 \mathrm{~nm}$.

\subsubsection{Spectral analysis of carotenoids}

The carotenoids of $A$. obtusiloba were extracted based on the method reported by Cai Xuan et al. [30] with necessary modifications. Briefly, each sample of flower powder $(0.1 \mathrm{~g})$ was mixed with acetone/ethanol $(1: 1, v / v)$, and the mixture was repeatedly extracted $24 \mathrm{~h}$ in a Soxhlet apparatus under dark conditions. After the filtrate was combined and diluted to $10 \mathrm{~mL}$, the spectral scanning was carried out with a range of $200-700 \mathrm{~nm}$.

\subsection{Qualitative and quantitative analysis of petal pigments}

Flavonoids in petals of $A$. obtusiloba were extracted with methanol/formic acid $(98: 2, \mathrm{v} / \mathrm{v})$ in darkness at $4^{\circ} \mathrm{C}$ for $24 \mathrm{~h}$. Then the mixture was centrifuged at $12,000 \mathrm{rpm}$ for $5 \mathrm{~min}$ at $4^{\circ} \mathrm{C}$ to remove the precipitants. The supernatant was collected and filtered through a $0.45 \mu \mathrm{m}$ micropore membrane, and the as-prepared sample was stored for qualitative and quantitative analysis. The experiment was repeated three times for each sample[31].

The quantitative analysis of flavonoids was performed on HPLC-PAD (Waters 2685, USA) and HPLC-MS (Agilent 6460,USA). A C18 column of Inertsil Zorbax SB (4.6 mm $\times 250 \mathrm{~mm}, 5 \mu \mathrm{m}$, Shimadzu GL, Shanghai, China) was used to separate the individual flavonoids with mobile phase $A$ (double distilled water containing $0.1 \%$ phosphoric acid) and mobile phase $B$ (acetonitrile). The elution gradient was set as follows: 0 min, 1\% B; 15min, 8\% B; 35min, 22\% B; 45 min, 42\% B; 55 min, 75\% B; 65 min, 100\% B. Then, 2 $\mu \mathrm{L}$ of the sample was injected for HPLC analysis. The chromatogram showed horizontal coordinate and vertical coordinate, corresponding to the retention time $(\mathrm{min})$ and response value $(\mathrm{mAU})$, respectively. The flow rate was $0.2 \mathrm{~mL} / \mathrm{min}$, and the column temperature was $30^{\circ} \mathrm{C}$. Since flavonoids are expected to be observed at a $300 \mathrm{~nm}$ wavelength by UV detector, the spectra were scanned in the range of $190-700 \mathrm{~nm}$.

The MS conditions were set as follows: High purity nitrogen (99.999\%) was used as a nebulizing (60 psi) and drying gas at a flow rate of $9.0 \mathrm{~L} / \mathrm{min}$. The vaporizer temperature was set at $350^{\circ} \mathrm{C}$. Other parameters were rationally set including an lonspray voltage of 70-205 Vand a scanning range of $100-1000 \mathrm{~m} / \mathrm{z}$.

\subsection{Statistical analysis}

The data were processed and presented as mean \pm standard deviation (SD). Experiments were performed in triplicates and the statistical analysis was executed by one-way analysis of variance (ANOVA).

Significant differences between groups were discerned at $p \leq 0.05$. Statistic software GraphPad Prism 6.0 (GraphPad Software Inc., San Diego, USA) was used for all the graphical and statistical evaluations.

\section{Result}

\subsection{Spectral analysisusing UV-vis spectrometer}




\subsubsection{Spectral analysis of flavonoids}

As shown in the UV-vis spectrum of the flavonoid fraction of A. obtusiloba (Figure 1A), the maximum absorption peaks were observed at $268 \mathrm{~nm}$ (band II) and $330 \mathrm{~nm}$ (band I), respectively. There are two typical absorbance bands of flavonoids, band B (310-350 nm) for flavones and band A (250-290 nm) for flavonols $[32,33,34]$. Generally speaking, band II absorption could be caused by ring A-cyclobenzoic acid system, while band I was caused by ring B-cyclocinnamic acid system $[35,36]$. As shown in Figure $1 \mathrm{~A}$, the absorption peak at $268 \mathrm{~nm}$ indicated the presence of the A-cyclobenzoyl system, while the absorption peak at $300 \mathrm{~nm}$ suggested that there was a B-cyclocinnamoyl system in the flavonoid fraction of the flower extract. Based on the observation that band II was the main peak while band I was weak, we speculated that the cinnamoyl system might be destroyed [37]. This result showed that the extract from A. obtusiloba had the basic structure of flavonoids C6-C3-C6.

\subsubsection{Spectral analysis of carotenoids}

According to the UV-vis spectrum of the carotenoid sample from A. obtusiloba (Figure 1B), the maximum absorption peak was at $268 \mathrm{~nm}$, which was consistent with the characteristic absorption peak of the carotenoid. With the deeper colour, the absorption peak of the carotenoid sample gradually increased. The total content changed regularly with the shading of the colour (Figure 1B). The maximum light absorption value of the pale-yellow sample was $18.36 \%$ less than that of the yellow sample (4.112 and 3.357 of the optical density (OD),respectively).

\subsection{Qualitative and quantitative analysis of petal pigments}

\subsubsection{Qualitative analysis of petal pigments from Maqu}

Based on the HPLC-PDA analysis of the flavonoid extract of yellow flowers of A. obtusiloba (Figure 2), 7 kinds of compounds were detected at $300 \mathrm{~nm}$ with a retention time ranging from 30 to $50 \mathrm{~min}$. Meanwhile, there were 8 kinds of compounds detected in light-yellow of flavonoid fraction of $A$. obtusiloba. Zhaoet al.[38] reported that the different colours of flowers were not determined by the structure of the compound, but by the change in the content of some pigment molecules. Studies have also found that the red colour of cotton is mainly caused by flavonoid accumulation. Except for the flavonoid-related enzymegenes in red cotton such as $\mathrm{CHS}$ and $\mathrm{F} 3^{\prime} \mathrm{H}$, other genes that regulate flavonoid biosynthesis have higher transcription levels than those in white cotton [39]. In the HPLC chromatogram (Figure 2A), peaks 3 and 8 were close to each other, suggesting that they might be isomers. Therefore, the flavonoid components of the two coloured flowers are supposed to be the same. Mostly, the peak intensity (response value) of yellow flowers (B)was higher than that of the light yellow(B) ones. Therefore, it could be suggested that the colour intensity of $A$. obtusiloba was caused by the content of pigment molecules. The components (Figure 2A) at peaks $3(1.775 \mathrm{mg} / \mathrm{g}), 6(1.56 \mathrm{mg} / \mathrm{g})$, and $7(2.687 \mathrm{mg} / \mathrm{g})$ 
were more dominant in light-yellow flowers, whereas peaks $3(4.124 \mathrm{mg} / \mathrm{g}), 4(2.754 \mathrm{mg} / \mathrm{g})$, and 7 $(2.651 \mathrm{mg} / \mathrm{g})$ were more dominant in yellow flowers (Figure 2B).

\subsubsection{Quantitative analysis of petal pigments from Maqu}

To further determine the specific type of pigment molecules, HPLC-MS analysis was carried out on yellow flowers with high total contents. The MS peaks of four standards (Quercetin, Kaempherol, Luteolin, and Rutin) were shown in Figure 3. According to the total ion chromatogram and positive ion mode of flavonoid from the yellow flower (Figure 4 and Figure 5), the analysis results in Table1 were obtained.

The molecular ion peak was observed at $\mathrm{m} / \mathrm{z} 645.18[\mathrm{M}+\mathrm{H}]+$ of peak 7 . The fragment at $\mathrm{m} / \mathrm{z} 465$ represented the loss of one glucose molecule. Then one glucose molecule was removed to obtain a fragment $\mathrm{m} / \mathrm{z} 287$, which was luteolin aglycone. It was speculated to be luteolin-3-7-0-glucoside since it was consistent with the result reported by Waage S.K et al. [40].

\section{Table 1}

HPLC-MS analysis results of flavonid from Anemone obtusiloba yellow flower

\begin{tabular}{|c|c|c|c|c|}
\hline $\begin{array}{l}\text { Peak } \\
\text { No》 }\end{array}$ & $\begin{array}{l}\text { Retention } \\
\text { time(min) }\end{array}$ & $\begin{array}{l}\text { Molecular } \\
\text { ion }(\mathrm{m} / \mathrm{z})\end{array}$ & $\begin{array}{l}\text { Fragment } \\
\text { ions } \\
(\mathrm{m} / \mathrm{z})\end{array}$ & Identification \\
\hline 7 & 31.88 & $645.18\left([\mathrm{M}+\mathrm{H}]^{+}\right)$ & $465 \rrbracket 287 \rrbracket 248$ & luteolin-3-7-0-glucoside \\
\hline 6 & 33.24 & $625.15\left([\mathrm{M}]^{+}\right)$ & $465 \rrbracket 303 \rrbracket 274$ & quercetin-3-0-rutoside \\
\hline 5 & 36.19 & $611.2\left([\mathrm{M}+\mathrm{H}]^{+}\right)$ & $445 \rrbracket 287 \rrbracket 263$ & $\begin{array}{l}\text { kaempferol-3-0- } \\
\text { sophoroside }\end{array}$ \\
\hline 4 & 42.58 & $483.1\left([\mathrm{M}+3 \mathrm{H}]^{+}\right)$ & $318 \rrbracket 146$ & myricetin-3-0-rhamnose \\
\hline 3 & 45.31 & $465.1\left([\mathrm{M}+\mathrm{H}]^{+}\right)$ & $303 \rrbracket 287 \rrbracket 274$ & quercetin-3-0-galactoside \\
\hline 2 & 45.74 & $465.1\left([\mathrm{M}+\mathrm{H}]^{+}\right)$ & $303 \rrbracket 287 \rrbracket 274$ & quercetin-3-0-glucoside \\
\hline 1 & 47.40 & $449.2\left([\mathrm{M}+\mathrm{H}]^{+}\right)$ & $303 \rrbracket 274 \rrbracket 179$ & quercetin-3-0-rhamnoside \\
\hline
\end{tabular}

The fragment at $\mathrm{m} / \mathrm{z} 303$ corresponded to quercetin aglytin and its cleaved m/z 274 fragments were found in MS of peaks $6,3,2$, and 1, which were presumed to be derivatives of quercetin. The $[\mathrm{M}+\mathrm{H}]+$ of peak 6 was $\mathrm{m} / \mathrm{z}$ 625.15, which contained fragment ions $\mathrm{m} / \mathrm{z} 465$ and 303, indicating that two molecules of six-carbon sugar have been removed. As a result, it could be quercetin-3-0-rutoside $[40,41]$. Besides, a molecular ion peak was observed at $\mathrm{m} / \mathrm{z} 465.1[\mathrm{M}+\mathrm{H}]+$ of peaks 3 and 2 , and the removal of one sixcarbon sugar molecule obtained $\mathrm{m} / \mathrm{z} 303$. This result could indicate that peak 3 was quercetin-3-0galactoside and peak 2 was quercetin-3-0-glucoside [42-45]. Fragments at m/z 303 showed that the 
removal of rhamnose and fragments at $\mathrm{m} / \mathrm{z} 179$ could be the loss of one water molecule representing the $[\mathrm{M}+\mathrm{H}]+$ peak 1 . The result indicated that it might be quercetin-3-0-rhamnoside [46]. The fragment ion $\mathrm{m} / \mathrm{z}$ 287 matched the molecular weight of kaempferol. Therefore, it could be speculated that kaempferol was contained in its structure. The fragment $\mathrm{m} / \mathrm{z} 445$ indicated the loss of two molecules of glucose, which was consistent with the peak of kaempferol-3-0-sophoroside reported previously [46]. The molecular ion peak 4 was observed at $\mathrm{m} / \mathrm{z} 483.1[\mathrm{M}+\mathrm{H}]+$. Based on the characteristic ion of myricetin at $\mathrm{m} / \mathrm{z} 318$, and the glycosyl ion at $\mathrm{m} / \mathrm{z} 146$, the data were found to be consistent with the result of myricetin-3-0rhamnose [47]. The content of the flavonoids was measured (Table 2). The content of quercetin-3-0galactoside $(4.124 \mathrm{mg} / \mathrm{g})$ was found to be relatively higher than the other components. As a result, quercetin derivatives were dominant in flavonoids of $A$. obtusiloba flowers. The result is the same as the Hezuo sample plot [49].

\section{Table 2}

The content of main components of anthocyanin in Maqu Anemone obtusiloba $(\mathrm{mg} / \mathrm{g})$

\begin{tabular}{|llll|}
\hline Peak No\} $&{\text { Component }} &{\text { Yellow flowers }} &{\text { Light yellow flower }} \\
{\hline 7} &{\text { luteolin-3-7-O-glucoside }} &{2.754} &{2.687} \\
{\hline 6} &{\text { quercetin-3-O-rutoside }} &{0.982} &{1.56} \\
{\hline 5} &{\text { kaempferol-3-O-sophoroside }} &{1.2} &{0.394} \\
{\hline 4} &{\text { myricetin-3-O-rhamnose }} &{2.651} &{0.34} \\
{\hline 3} &{\text { quercetin-3-O-galactoside }} &{4.124} &{1.775} \\
{\hline 1} &{\text { quercetin-3-O-glucoside }} &{0.867} &{0.815} \\
{\hline}$
\end{tabular}

\subsection{The key enzyme analysis in the regulation of anthocyanin in A. obtusiloba}

Although the anthocyanins of $A$. obtusiloba are mainly composed of four sugar derivatives of luteolin, kaempferol, myricetin and quercetin, In these major flavonoids, quercetin with the highest relative abundance may be one of the main active ingredients. According to the metabolic pathway of flavonoids (Figure 6) [48], quercetin could only be synthesized from dihydroquercetin and catalysed by flavonol synthetase (FLS). There were two pathways of dihydroquercetin synthesis: one was eriodictyol catalysed by flavanone-3-hydroxylase (F3H), and the other was dihydrokaempferol catalysed by flavonoid-3'hydroxylase (F3'H). However, eriodictyol could be also catalysed by flavone synthase II (FNSII) to form luteolin. In the study, the derivatives of luteolin $(2.754 \mathrm{mg} / \mathrm{g})$ were observed. Therefore, luteolin pathway 
was not prohibited, and the activity of FNSII might be reduced or the gene expression of FNSII was down regulated to reduce the decomposition of luteolin. F3'H catalysed the synthesis of dihydrokaempferol and dihydroquercetin from senkyolin and naringenin, respectively. According to the reactions in Figure 6, F3' $\mathrm{H}$ showed ahigher affinity with naringenin. So it was speculated that the affinity of FLS with dihydrophlorin was enhanced in the pathway of the synthesis of luteolin, which competed with dihydrokaempferol and dihydromyricetin to increase the content of quercetin. According to the content of flavonoids in $A$. obtusiloba, it was speculated that the dihydrokaempferol pathway improved the translation of F3'Hto increase the content of dihydroquercetin. And the affinity between FLS and dihydroquercetin was enhanced, so quercetin content could be eventually increased.

Therefore, enhancing the translation of F3' $\mathrm{H}$ gene could not only increase the content of dihydroquercetin, but also increase the content of eriodictyol, which could indirectly increase the content of dihydroquercetin and finally achieve the purpose of increasing the content of quercetin.

\section{Discussion}

In recent years, with changes in the environment in the alpine region, the pigment of the unique plant $A$. obtusiloba has also been changed. In the Hezuo plot with lower altitudes, the pigment of $A$. obtusiloba has undergone significant changes to adapt to the environment, the pigment of the $A$. obtusiloba is obviously darkened. Compared with low altitude Hezuo plot, the higher the altitude, the deeper the color, In the Maqu plot with higher altitudes, and even no white flowers are observed (Figure 7). The main anthocyanins in the two places are the same, and the change trend of main pigments was consistent with the change of flower color (Table3) [49].

In this study, the main components and their key enzymes in different colourful flowers of $A$. obtusiloba were analysed by UV-vis spectroscopy, HPLC-PAD, and HPLC-MS. Seven kinds of components in flavonoids were speculated by HPLC-MS, including luteolin-3-7-0-glucoside, quercetin-3-0-rutoside, quercetin-3-0-galactoside, quercetin-3-0-glucoside, quercetin-3-0-rhamnoside, kaempferol-3-0sophoroside, and myricetin-3-0-rhamnose. According to the results of qualitative and quantitative analysis, quercetin showed the largest proportion of sugar derivatives and the most obvious change of flower colour. It is the main chromogenic pigment that causes the difference in flower colour of $A$. obtusiloba. According to the flavonoid metabolic pathways, there are three main ways to increase the content of quercetin: (1) reducing the activity of FNS $₫$ or attenuating the translation of FNSII gene to reduce the path of eriodictyol; (2) enhancing the affinity of FLS binding with dihydroquercetin to make dihydroquercetin superior in substrate competition; (3)enhancing the translation of F3'H genes, such as increasing the transcription factor in the promoter region to increase the content or activity of $\mathrm{F}^{\prime} \mathrm{H}$ to increase the contents of dihydroquercetin and saugenin.

\section{Table 3}

The content of main components of anthocyanin in Hezuo Anemone obtusiloba $(\mathrm{mg} / \mathrm{g})[49]$ 


\begin{tabular}{|lllll|}
\hline Peak No\} $&{\text { Component }} &{\text { Yellow flowers }} &{\text { Light yellow flower }} &{\text { White flowers }} \\
{\hline 7} &{\text { luteolin-3-7-O-glucoside }} &{2.057} &{1.533} &{0.666} \\
{\hline 6} &{\text { quercetin-3-O-rutoside }} &{1.667} &{0.812} &{0.213} \\
{\hline 5} &{\text { kaempferol-3-O-sophoroside }} &{1.661} &{0.922} &{0.256} \\
{\hline 4} &{\text { myricetin-3-O-rhamnose }} &{1.627} &{1.024} &{0.211} \\
{\hline 3} &{\text { quercetin-3-O-galactoside }} &{2.325} &{1.431} &{0.769} \\
{\hline 2} &{\text { quercetin-3-O-glucoside }} &{1.255} &{0.613} &{0.075} \\
{\hline 1} &{\text { quercetin-3-O-rhamnoside }} &{2.459} &{0.92} &{0.233} \\
{\hline}$
\end{tabular}

Compared with the content of main pigment components in low altitude Hezuo plots (Table3), it can be analyzed that quercetin-3-o-galactoside of peak 3, myricetin-3-o-rhamnoside of peak 4 and luteolin-3-7-odiglucoside of peak 7 are the main pigments with high content. However, the pigments that affect the color change are quercetin-3-o-galactoside, quercetin-3-o-rhamnoside, myricetin-3-o-rhamnoside and kaempferol-3-o-sophoroside, but the content of quercetin derivatives accounts for the highest proportion. Based on the results of this study, quercetin was identified as the main pigment of A. obtusiloba. The key enzyme to adapt to the environment was discovered to be $\mathrm{F}^{\prime} \mathrm{H}$. The main environmental factor causing pigment change may be light intensity. This paper speculates that $A$. obtusiloba increases the content of quercetin by regulating the expression or activity of F3' $\mathrm{H}$ to deepen the flower colour so that it could adapt to the environment. In this study, the evolution of $A$. obtusiloba response to the environment was analysed. This conjecture is also applicable to the adaptation to altitude changes. It provides a theoretical basis for the study of the evolution mechanism of plateau plants responding to the environment and provides a reference for the relationship between plateau environmental change and vegetation.

\section{Declarations}

\section{Acknowledgements}

Thanks for the financial support provided by Lanzhou University of Technology

\section{Conflicts of interest/Competing interests}

No conflict of interest exits in the submission of this manuscript, and all the authors listed have approved the manuscript that is enclosed.

\section{Statement}


Ethical approval: This article does not contain any studies with human participants performed by any of the authors.

Ethical approval: This article does not contain any studies with animals performed by any of the authors.

Ethical approval: This article does not contain any studies with human participants or animals performed by any of the authors.

\section{Data availability/Availability of Data and Materials Statements}

The datasets used and/or analysed during the current study available from the corresponding author on reasonable request.

\section{Collect Anemone obtusiloba Premissions Statement}

School of life sciences, Lanzhou University of Technology and College of grassland agricultural science and technology, Lanzhou University had given a permission to collect Anemone obtusiloba on the sample plot.

Collection of Anemone obtusiloba comply with relevant institutional, national, and international guidelines and legislation.

All these voucher specimens are deposited in the public collection providing access and Author Lv wanling and Professer Liu zuojun identified it.

\section{References}

1. Thu Z.M., Aye M.M., Aung H.T., SeinM.M., Vidari G,(2018).A Review of Common Medicinal Plants in Chin State, Myanmar, Natural Product Communications,13 (11). PP:1557-1567. https://doi.org/ 10.1177/1934578X1801301134

2. Tan G.L®Du G.Z囚Li Z.Z,Yang G.Y, Ma J.Y,Niang M.J,(2002).Relationship between productivity and species diversity in alpine meadow plant community.J Plant Ecol,26: 57-62区https://doi.org/ CNKI:SUN:ZWSB.0.2002-S1-007

3. Masood M., Ashok P., Tiwari K.P, (1979).Obtusilobinin and obtusilobin, two new triterpene saponins from Anemone obtusiloba,Phytochemistry, 18(9). PP:1539-1542. https://doi.org/ 10.1016/S00319422(00)98492-9.

4. Tiwari K.P., Masood M, (1979).Obtusilobicinin, a new saponin from Anemone obtusiloba,Phytochemistry, 19(6). pp:1244-1247. https://doi.org/10.1016/0031-9422(80)83099-8 
5. Savita R., Sanjeev K.,Mudassir J.S.,Santosh K., Chand G.R, (2011).Cytological studies in some members of family Ranunculaceae from Western Himalayas (India)," Caryologia, 64(4). pp:408-415. https://doi.org/10.1080/00087114.2011.10589808

6. Gupta A.K., Sharma M., Chandha A,(2005).Reviews on Indian Medicinal Plants, Journal of Ethnopharmacology. 96(3). pp:0972-7957.https://doi.org/10.1016/j.jep.2004.09.001.

7. Khare C.P.,(2007).Indian medicinal plants: An illustrated dictionary. Springer, New York.ISBN:978-0387-70637-5.

8. Grotewold E,(2006). The genetics and biochemistry of floral pigments.Annual Review of Plant Biology, 57(1). pp:761-780. https://doi.org/10.1146/annurev.arplant.57.032905.105248.

9. Pang Z.S.,(2000).Research advance of anthocyanins,Beijing Agricultural Sciences, 18. pp:37-42.

10. Harborne J.B.,(1993). Introduction to ecological biochemistry. Academic press, London, pp:3670.https://doi.org/10.1016/0305-1978(94)90064-7.

11. Tanaka Y., Sasaki N., Ohmiya A,(2008).Biosynthesis of plant pigments: anthocyanins, betalains and carotenoids. The Plant Journal. 54(4) pp:733-749.https://doi.org/10.1111/j.1365-313X.2008.03447.x

12. Hall M.A, (1897).Plant structure, function and adaptation. Beijing: Science Press, pp:221-258. https://doi.org/10.1007/978-1-349-06571-4.

13. Gao G., Chen P., Chen J.K., Chen K.M., Wang X.F., Shehu A.A., Liu N., Yu C.M., Zhu A.G, (2019).Genomic survey, transcriptome, and metabolome analysis of apocynum venetum and apocynum hendersonii to reveal major flavonoid biosynthesis pathways, Metabolites, 9(12).pp: 1-15. https://doi.org/10.3390/metabo9120296.

14. Brenda W.S., (2001).Flavonoid biosynthesis, A colorful model for genetics, biochemistry, cell biology, and biotechnology.Plant Physiology, 126(2), pp:485-493.https://doi.org/10.1104/pp. 126.2.485.

15. Arora S., Itankar P.,(2018). Extraction, isolation and identification of flavonoid from Chenopodium album aerial parts, Journal of Traditional and Complementary Medicine, 8(4). pp:476482.https://doi.org/10.1016/j.jtcme.2017.10.002.

16. Tohge T.,De Souza L.P., Fernie A.R.,(2017). Current understanding of the pathways of flavonoid biosynthesis in model and crop plants. Journal of Experimental Botany, 68(15)pp: 4013-28. https://doi.org/10.1093/jxb/erx177.

17. Zhang L.,Su W., Tao R., Zhang W., Chen J., Wu P., (2017).RNA sequencing provides insights into the evolution of lettuce and the regulation of flavonoid biosynthesis. Nature Communications, 8(1). pp:112. $h t t p s: / / d o i . o r g / 10.1038 / s 41467-017-02445-9$.

18. Liu L.Li Y., She G., Zhang X., Jordan B., Chen Q, (2018).Metabolite profiling and transcriptomic analyses reveal an essential role of UVR8-mediated signal transduction pathway in regulating flavonoid biosynthesis in tea plants (Camellia sinensis) in response to shading.BMC Plant Biol, 18. pp:233-250.https://doi.org/10.1186/s12870-018-1440-0

19. Deng Y., Li C., Li H., Lu S, (2018). Identification and characterization of flavonoid biosynthetic enzyme genes in Salvia miltiorrhiza (Lamiaceae).Molecules, 23(6). pp:1467-

86.https://doi.org/10.3390/molecules23061467. 
20. Deshmukh A.B., Datir S., Bhonde Y., Kelkar N., Samdani P, (2018).De novo root transcriptome of a medicinally important rare tree Oroxylum indicumfor characterization of the flavonoid biosynthesis pathway.Phytochemistry, 156. pp:201-213. https://doi.org/10.1016/j.phytochem.2018.09.013.

21. Yue J., Zhu C., Zhou Y., Niu X., Miao M., Tang X., Chen F.D., Zhao W.P.,Liu Y.S., (2018).Transcriptome analysis of differentially expressed unigenes involved in flavonoid biosynthesis during flower development of Chrysanthemum morifolium 'Chuju'.Scientific Reports, 28(1). pp:13414-13441. https://doi.org/10.1038/s41598-018-31831-6.

22. Jiang Y., Ji X., Duan L., Ye P., Yang J., Zhan R. Chen W.W., Ma D.M., (2019).Gene mining and identification of a flavone synthase II involved in flavones biosynthesis by transcriptomic analysis and targeted flavonoid profiling in Chrysanthemum indicumL.. Industrial Crops and Products, 134(1). pp:244-256. https://doi.org/10.1016/j.indcrop.2019.04.009

23. Zhao Q. Zhang Y., Wang G., Hill L., Weng J., Chen X., Xue H.W., Martin C, (2016).A specialized flavone biosynthetic pathway has evolved in the medicinal plant, Scutellaria baicalensis. Science Advances.2(4).e1501780-e1501780.https://doi.org/10.1126/sciadv. 1501780.

24. Ferreyra M.L.F., Rius S.P., Casati P,(2012).Flavonoids: Biosynthesis, biological functions, and biotechnological applications. Frontiers in Plant Science, 3(1).pp:222-

237.https://doi.org/10.3389/fp/s.2012.00222.

25. Martens S., Mithöfer A,(2005). Flavones and flavone synthases. Phytochemistry, 66(20). pp:23992407.https://doi.org/10.1016/j.phytochem.2005.07.013

26. Zhu J.Y., Xu Q.S., Zhao S.Q., Xia X.B., Yan X.M., An Y.L., Mi X.Z., Guo L.X., Samarina, L., Wei C.L., (2020).Comprehensive co-expression analysis provides novel insights into temporal variation of flavonoids in fresh leaves of the tea plant (Camellia sinensis). Plant Science. 290(1).pp:110306110317.https://doi.org/10.1016/j.plantsci.2019.110306

27. Patra B., Schluttenhofer C., Wu Y., Pattanaik S., Yuan L.,(2013). Transcriptional regulation of secondary metabolite biosynthesis in plants. Biochim Biophys Acta.1829(11). pp:12361247.https://doi.org/10.1016/j.bbagrm.2013.09.006

28. Takeuchi A., Matsumoto S., Hayatsu M.,(1995).Effects of shading treatment on the expression of the genes for Chalcone synthase and phenylalanine ammonialyase in tea plant (Camellia sinensis).Bulletin of the National Research Institute of Vegetable Ornamental Plantsand Tea, 8(1). 19. https://doi.org/10.7525/j.issn.1673-5102.2016.02.010

29. Deepika M.S., Thangam R., Sakthidhasan P., Arun S., Sivasubramanian S., Thirumurugan. R, (2018).Combined effect of a natural flavonoid rutin from Citrus sinensis and conventional antibiotic gentamicin on Pseudomonas aeruginosa biofilm formation.Food Control, 90(1). pp:282-294. https://doi.org/10.1016/j.foodcont.2018.02.044

30. Cai X., Su F., Jin H.X, Yao C.H., Wang C.Y., (2010).Components and extraction methods for petal pigments of Osmanthus fragrans Siji Gui'.Journal of Zhejiang Forestry College, 27(4). pp:559-564. https://doi.org/1000-5692ロ2010ロ04-0559-07 
31. Wang Y.,Zhang C., Dong B., Fu J., Hu S., Zhao H, (2018).Carotenoid Accumulation and Its Contribution to Flower Coloration of Osmanthus fragrans.Frontiers in Plant Science, 9. pp:1-17. https://doi.org/10.3389/fp/s.2018.01499

32. Sultana S,Vandana J. (2018). Development and validation of a RP-HPLC method for the simultaneous determination of quercetin, ellaficacidandrutini hydroalcoholic extract of Triphala Churna. International Journal of Applied Pharmaceutics,10(3).https://doi.org/10.22159/ijap.2018v10i3.25860..

33. Tsimogiannis D., Samiotaki M., Panayotou G., Oreopoulou V, (2007). Characterization of flavonoid subgroups and hydroxy substitution by HPLC-MS/MS.Molecules, 12(3). pp:593606.https://doi.org/10.3390/12030593

34. Arora S., Itankar P.,(2018). Extraction, isolation and identification of flavonoid from Chenopodium album aerial parts. Journal of Traditional and Complementary Medicine, 8(4).pp: 476482.https://doi.org/10.1016/j.jtcme.2017.10.002

35. Hu Z.Q., Yang X.D., Chu L.S., Liu X.H,(1994).Separation and identification of flavonoids in green tea. Territory \& Natural Resources Study, 2.pp:63-68. https://doi.org/10.19813/j.cnki.weishengyanjiu.1993.03.011

36. Hu H.P., Han Y.L. Zhang F., Zhang D.M., Li S.J., (2008). Extraction of PawpawFlavoids and its Ultraviolet Spectrum Characteristic.Modern Food Science and Technology, 24(3).pp: 250-252. https://doi.org/1673-9078(2008)03-0250-03

37. Liu J.B., Lin S.Y., Wang Z.Z., Wang E.L., (2007).Study on Structure Identification of Flavonoids in Vaccinium uliginosum. L.Food science,28(9). pp:89-91. https://doi.org/1002-6630(2007)09-0089-03.

38. Zhao C.L., Guo W.M., Chen J.Y., (2005).Formation and regulation of flower color in higher plants. Chin Bull Bot, 22(1) pp:70-81.https://doi.org/10.3969/j.issn.1674-3466.2005.01.013

39. Long L., Liu J., Gao Y., Xu F.C., Zhao J.R., Li B., Gao W, (2019).Flavonoid accumulation in spontaneous cotton mutant results in red coloration and enhanced disease resistance.Plant Physiology and Biochemistry, 143(1). pp:40-49. https://doi.org/10.1016/j.plaphy.2019.08.021

40. Susan K. Waage, Paul A. Hedin, (1985). Quercetin 3-0-galactosyl-(1 $\rightarrow 6)$-glucoside, a compound from narrowleaf vetch with antibacterial activity. Phytochemistry, 24(2). pp:243245.https://doi.org/10.1016/S0031-9422(00)83528-1.

41. Louati S., Simmonds M.S.J., Grayer R.J, (2003).Flavonoids from Eriobotrya japonica (Rosaceae) growing in Tunisia.Biochemical Systematics and Ecology, 31(1). pp:99-101. https://doi.org/10.1016/S0305-1978(02)00072-8

42. Harborne J.B., Williams C.A, (1971).Leaf survey of flavonoids and simple phenols in the genus Rhododendron. Phytochemistry, 10 (11). pp:2727-2744.https://doi.org/10.1016/S00319422(00)97273-X.

43. Yu Y.Q., Gong Z.J., Li R, (2007).Simultaneous determination of hyperosid, isoquercitrin and quercetin in kendir extracturm by high performance liquid chromatographic method. Journal of Fudan University(Natural Science), 46. pp:417-420. https://doi.org/10.15943/j.cnki.fdxb-jns.2007.03.028. 
44. Harborne J.B.,(1986).Flavonoid patterns and phytogeography: the genus Rhododendron section Vireya.Phytochemistry, 25(7). pp:1641 -1643. https://doi.org/10.1016/S0031-9422(00)81226-1

45. Harborne J.B.,(1962).Plant polyphenols: 5.Occurrence of azalein and related pigments in flowers of Plumbago and Rhododendron species..Archives of Biochemistry and Biophysics, 96(1). pp:171178.https://doi.org/10.1016/0003-9861(62)90467-8.

46. Li C.H., Wang L.S., Shu Q.Y., Xu Y.J., Zhang J., (2008).Pigments Composition of Petals and Floral Color Change Duringthe Blooming Period in Rhododendron mucronulatum.Acta Horticulturae Sinica, 35(1). pp:1023-1030. https://doi.org 10.16420/j.issn.0513-353x.2008.07.015.

47. Chosson E., Chaboud A., Chulia A.J., Raynaud J,(1998). A phloracetophenone glucoside from Rhododendron ferrugineum.Phytochemistry, 47(1). pp:87-88.https://doi.org/10.1016/S00319422(97)00475-5.

48. He J., Yang W.J, Cheng B., Ma L., Tursunjiang D., Ding Z.M, Li Y., Wang Z.F., Ma Y.M, Li G,(2020). Integrated metabolomic and transcriptomic profiling reveals the tissue-specific flavonoid compositions and their biosynthesis pathways in Ziziphora bungeana. Chinese Medicine, 15(73). pp:73-73.https://doi.org/10.1186/s13020-020-00354-6.

49. Lv W L, Liu Z J, Zhang X R, Wang Y X, (2019). Research of Anemone obtusiloba main pigment composition and mechanism of adaptation. Natural Product Research and Development, 31,pp:395400.https://doi.org/10.16333/j.1001-6880.2019.3.004.

\section{Figures}



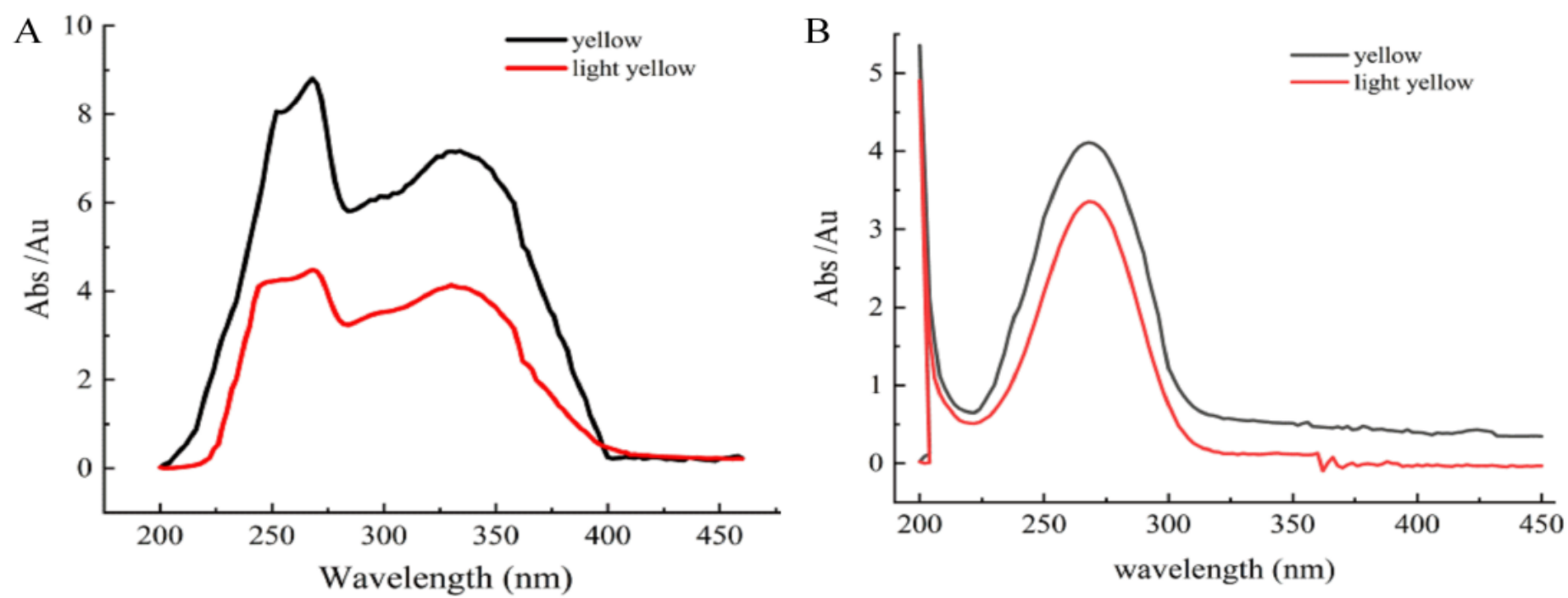

Figure 1

The UV-visible spectra of petal pigments in Anemone obtusiloba Flavonoid(A), Carotenoid(B).
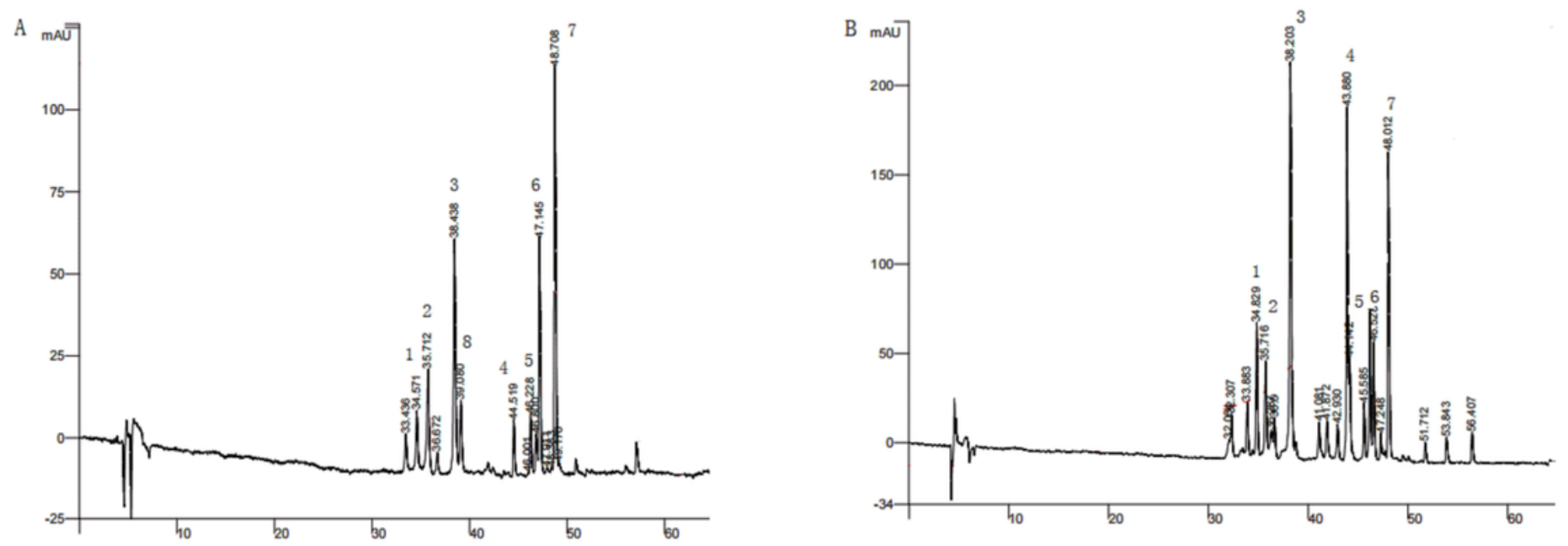

Figure 2

HPLC chromatogram of flavonids from Anemone obtusiloba Light yellow(A),yellow(B) 

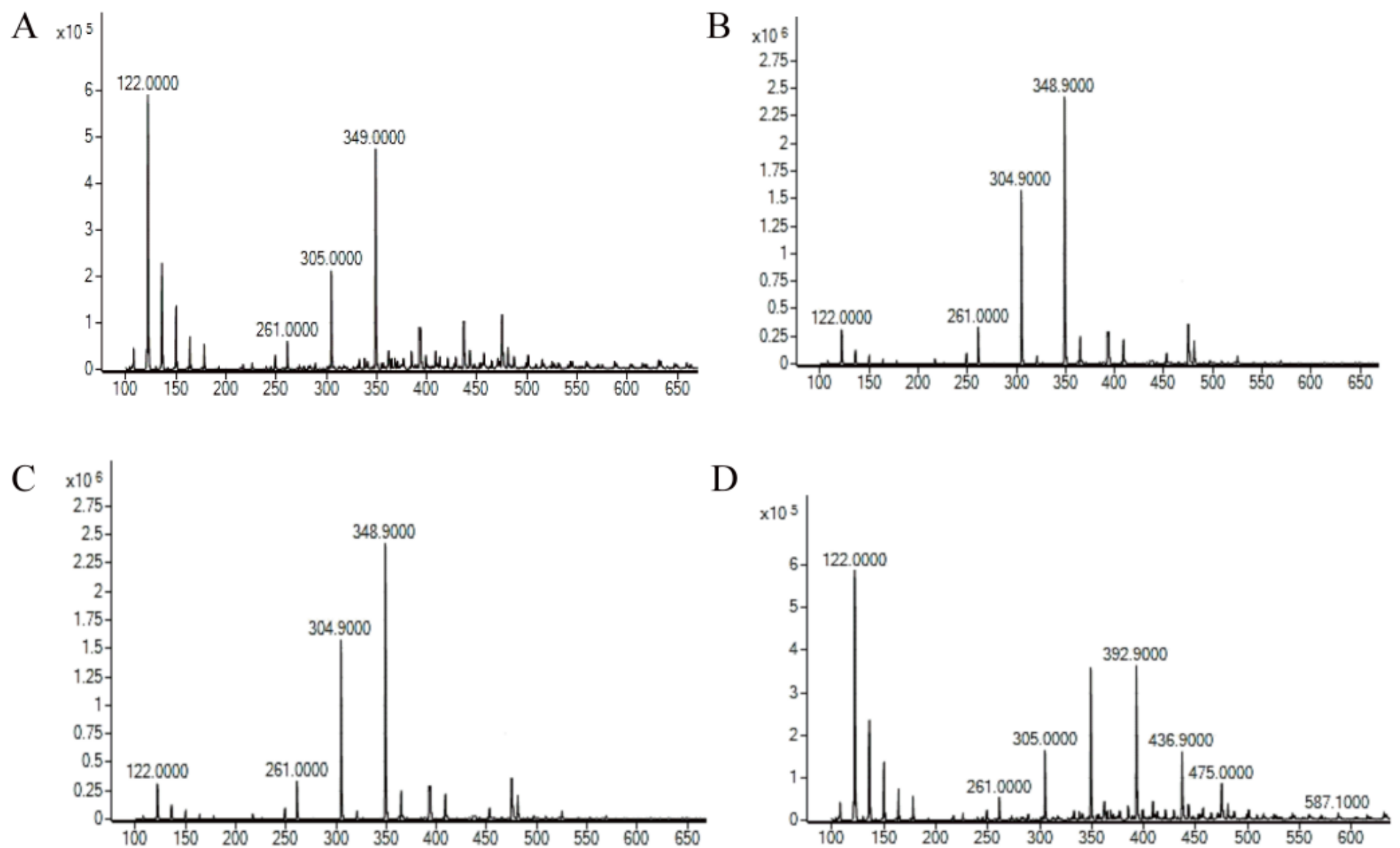

\section{Figure 3}

Total ion chromatogram of standards Lquercetin (A), Kaempherol (B), Luteolin (C), and quercetin-3-Orutinoside (D)
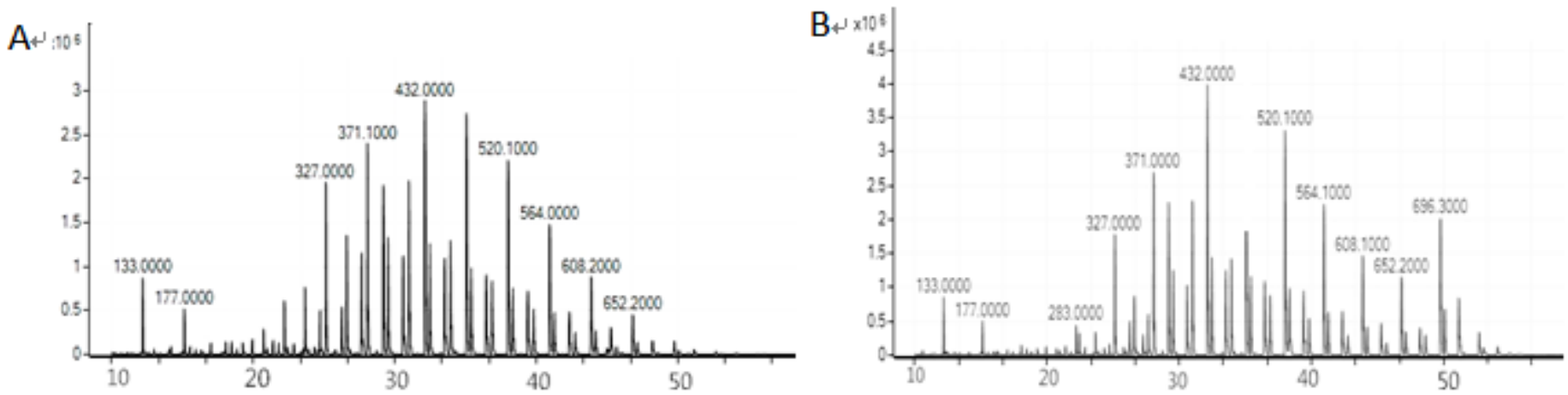

Figure 4

Total ion chromatogram of flavonoid from Anemone obtusiloba Light yellow(A),yellow(B) 


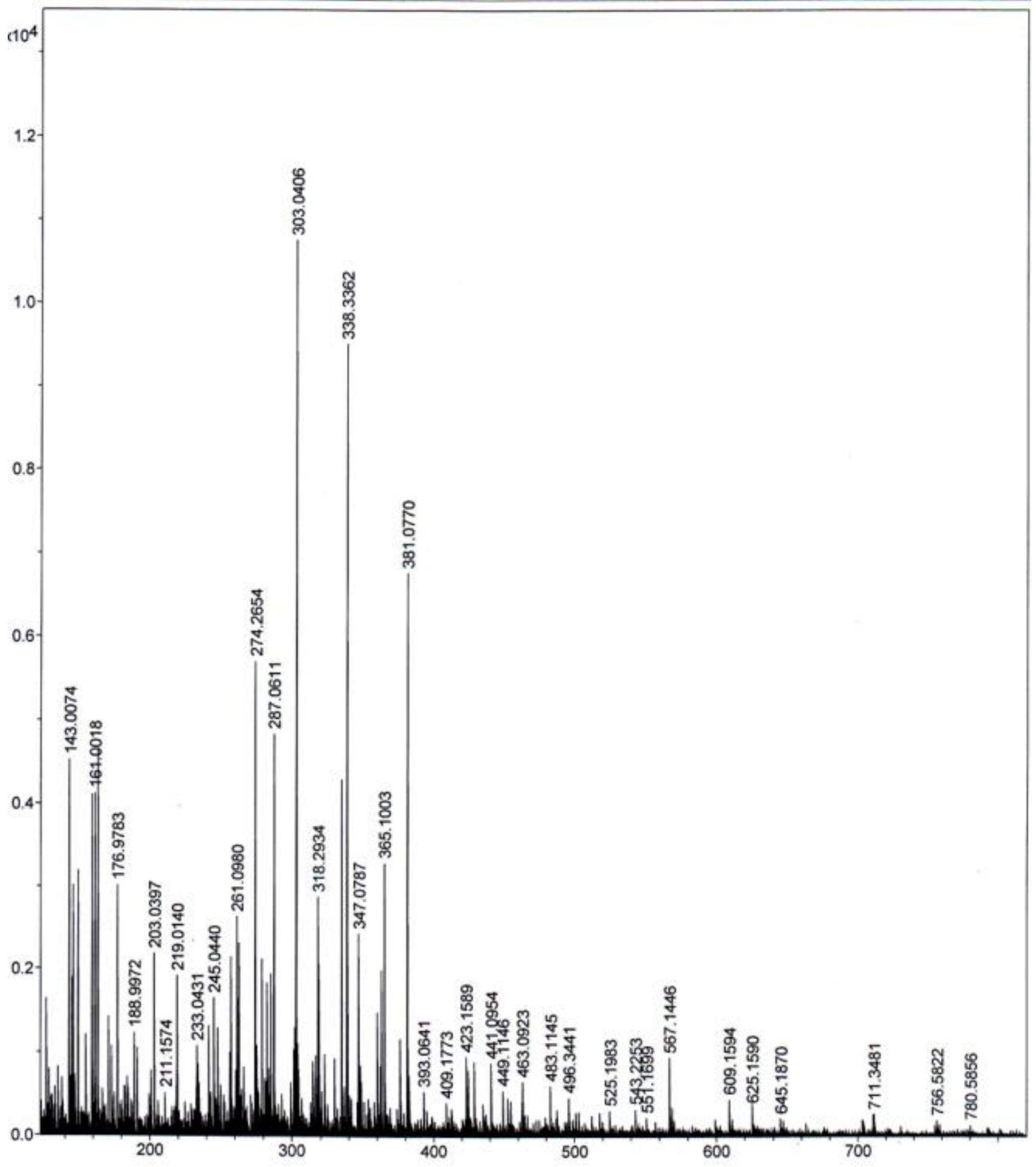

Figure 5

Cationic mass spectrograms of flavonoid from yellow Anemone obtusiloba 


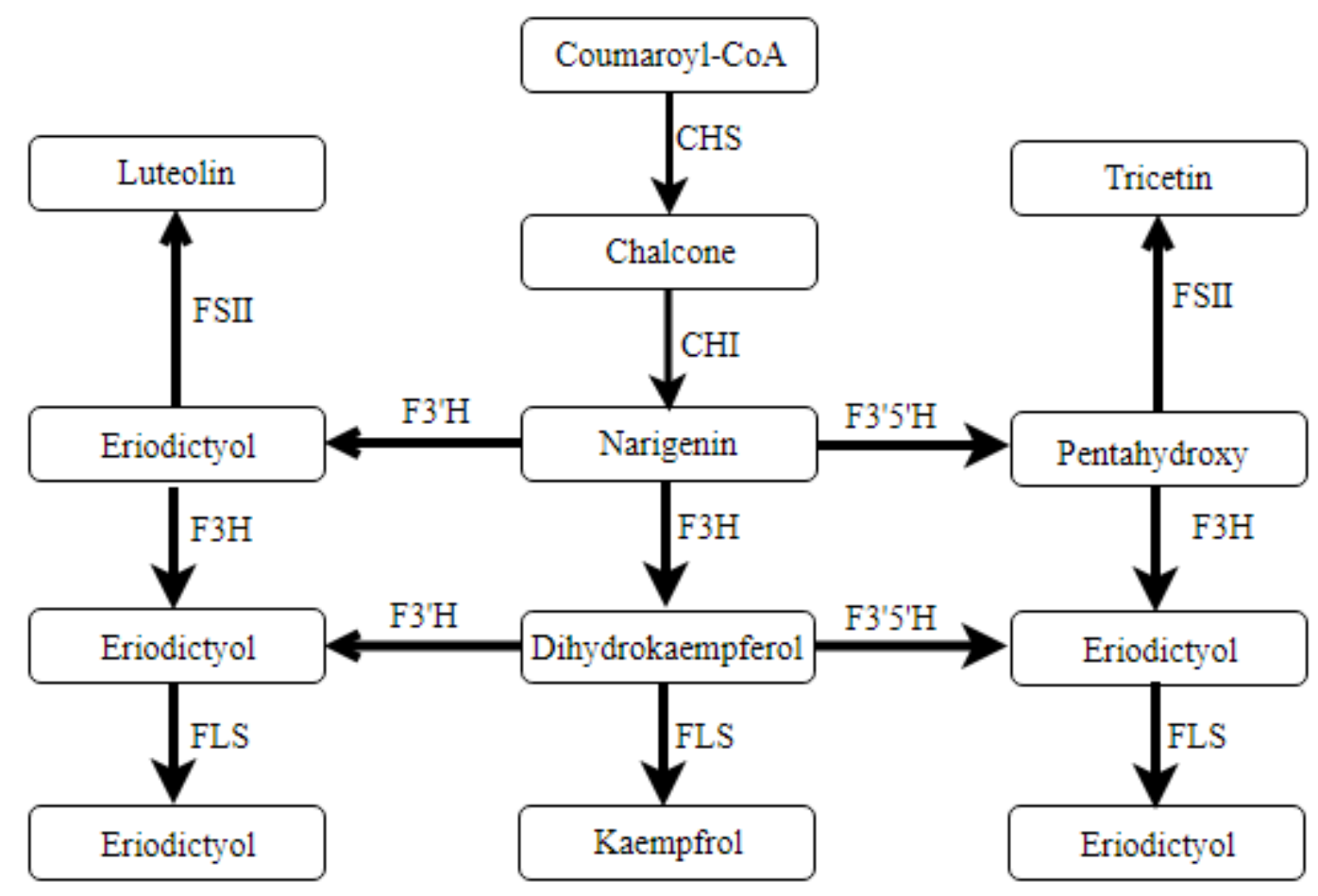

Figure 6

The metabolic pathway of flavonoid 


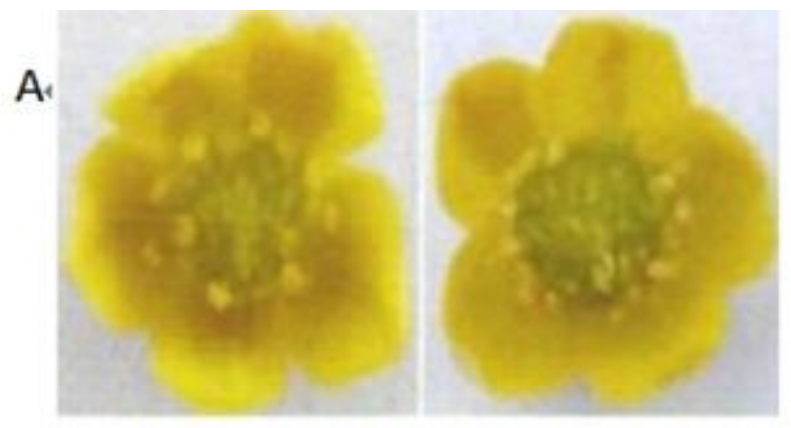

B.
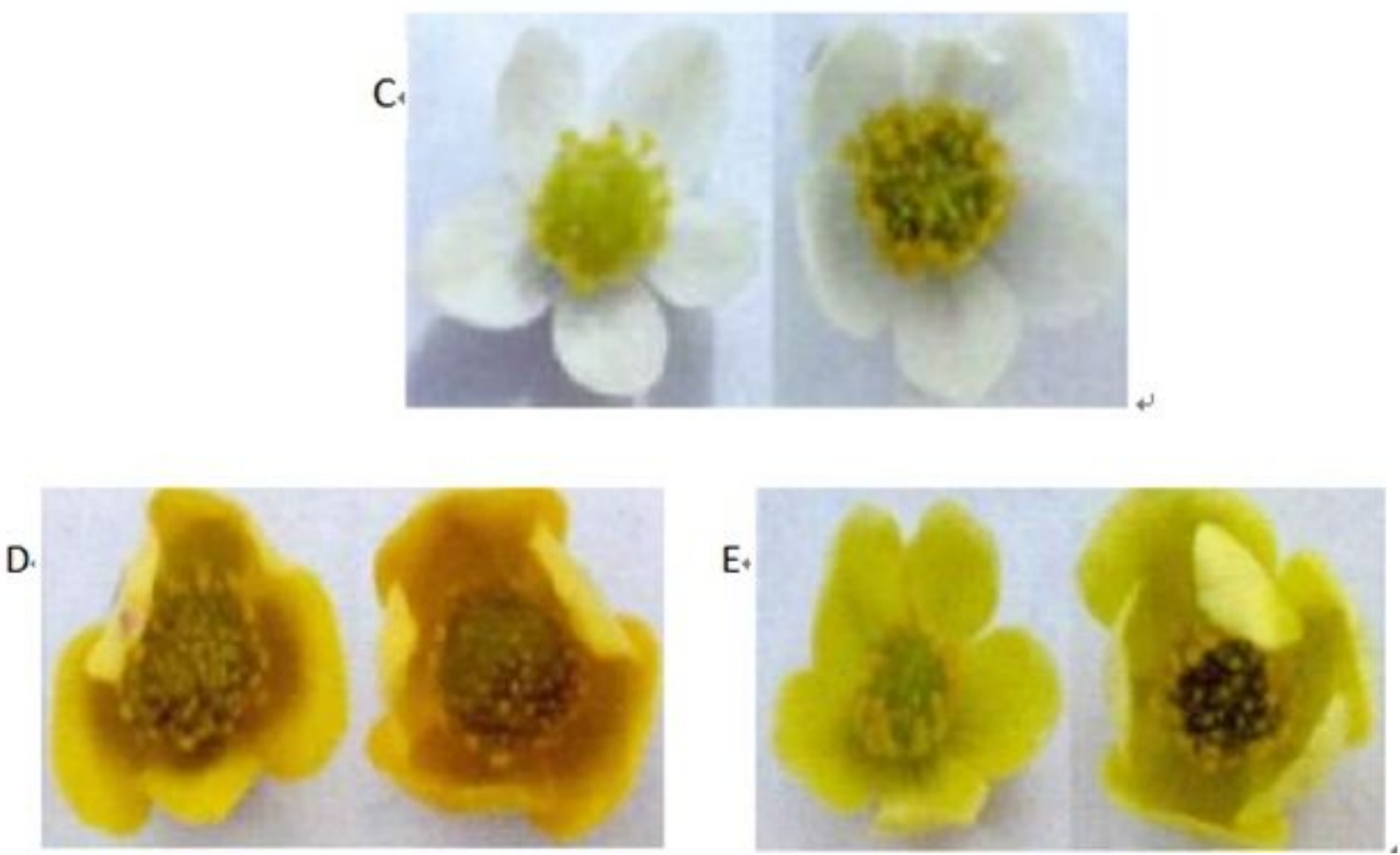

Figure 7

Three Pigment of Anemone obtusiloba.(A)Hezuo Yellow, (B)Hezuo Pale Yellow, (C)Hezuo White, (D)Maqu Yellow and (E)Maqu Pale Yellow.

\section{Supplementary Files}

This is a list of supplementary files associated with this preprint. Click to download.

- MaquLightyellow.pdf

- MaquMS.pdf

- MaquYellow.pdf 